\title{
PESQUISA DE CAMPO EM TERRITÓRIO TRADICIONAL NA \\ FRONTEIRA BRASIL/PARAGUAI
}

\author{
FIELD RESEARCH IN TRADITIONAL TERRITORY ON THE \\ BRAZIL/ PARAGUAY BORDER
}

\section{INVESTIGACIÓN DE CAMPO EN TERRITORIO TRADICIONAL EN LA FRONTERA BRASIL/ PARAGUAY}

\author{
Andréa L. Cavararo Rodrigues ${ }^{1}$ \\ Ciências Sociais pela Universidade Federal do Mato \\ Grosso do Sul (UFMS), Campo Grande, MS. \\ E-mail: andreacavararo@hotmail.com \\ Antonio H. Aguilera Urquiza ${ }^{2}$ \\ Pós-Graduação em Direitos Humanos da UFMS e do Programa \\ de Pós-Graduação em Antropologia Social (UFMS) e \\ Professor colaborador da Pós-Graduação em \\ Educação (UCDB). Campo Grande, MS. \\ E-mail: hilarioaguilera@gmail.com
}

\begin{abstract}
Resumo: Este texto traz um relato de experiência e reflexão acerca da importância do trabalho de campo na região fronteiriça envolvendo territórios tradicionais. $\mathrm{O}$ objetivo é descrever as vivências e experiências adquiridas no trabalho de campo no território tradicional kaiowá, na fronteira Brasil/Paraguai. Mesmo diante das dificuldades encontradas no Oguata, utilizando a terminologia guarani sobre o significado de caminhada, essa experiência foi muito rica, proporcionando momentos de reflexão, questionamentos e até mesmo indignação diante do panorama que se verifica a partir da convivência com a população Kaiowá - Paĩ Tavyterã, pois as dificuldades que já enfrentaram, e ainda enfrentam, para viver no território tradicional ainda persistem e estão longe de terminar. A base metodológica é própria dos estudos antropológicos, com interface no direito dos povos tradicionais e, além da pesquisa bibliográfica, manteve-se a preferência pelo trabalho de campo. O estudo permite concluir que o trabalho de campo e o envolvimento do pesquisador acadêmico com apoio do professor orientador favorecem a formação e consolidação do nível de excelência nos resultados alcançados.
\end{abstract}

Palavras-chave: Trabalho de campo, Povos tradicionais, Região fronteiriça.

1 Mestra em Antropologia Social pela Universidade Federal de Mato Grosso do Sul. Especialista em Antropologia História dos Povos Indígenas pela Universidade Federal do Mato Grosso do Sul. Bacharel em Ciências Sociais pela Universidade Federal do Mato Grosso do Sul. E-mail: andreacavararo@hotmail.com

2 Professor Associado da UFMS, orientador da pesquisa. Pesquisador do CNPq. Bolsista Produtividade (PQ2). Possui Doutorado em Antropologia pela Universidade de Salamanca/Espanha; atualmente é docente do curso de Ciências Sociais. 
ABSTRACT: This text brings a report experience and reflection on the importance of fieldwork in the border's zone of traditional territories. The objective is to describe the experiences acquired in the fieldwork in the traditional Kaiowá territory, on the Brazil / Paraguay border. Even with the difficulties found in Oguata, using the guarani terminology about the meaning of walking, this experience was extraordinarily rich, providing moments of reflection, questioning and even indignation at the panorama that can be seen from the coexistence with the Kaiowá - Paĩ Tavyterã population, because the difficulties they have already faced, and still face, to live in traditional territory persist and are far from over. The methodological basis is typical of anthropological studies, with an interface in the law of traditional peoples and, in addition to bibliographic research, the preference for fieldwork was maintained. The study allows us to conclude that the fieldwork and the involvement of the academic researcher with the support of the supervising professor favor the formation and consolidation of the level of excellence in the results achieved.

KEYWORDS: Fieldwork. Traditional peoples. Border's zone.

RESUMEN: Este texto trae un relato de experiencia y reflexión sobre la importancia del trabajo de campo en la región fronteriza involucrando territorios tradicionales. El objetivo es describir las experiencias adquiridas en el trabajo de campo en el territorio tradicional Kaiowá, en la frontera Brasil / Paraguay. Aún con las dificultades encontradas en Oguata, utilizando la terminología guaraní sobre el significado de caminar, esta experiencia fue muy rica, brindando momentos de reflexión, cuestionamiento e incluso indignación ante el panorama que se verifica desde la convivencia con la población Kaiowá - Paĩ. Tavyterã, porque las dificultades que ya enfrentaron, y aún enfrentan, para vivir en territorio tradicional aún persisten y están lejos de terminar. La base metodológica es propia de los estudios antropológicos, con interfaz en el derecho de los pueblos tradicionales y, además de la investigación bibliográfica, se mantuvo la preferencia por el trabajo de campo. El estudio permite concluir que el trabajo de campo y la implicación del investigador académico con el apoyo del profesor supervisor favorecen la formación y consolidación del nivel de excelencia en los resultados alcanzados.

PALABRAS CLAVE: Trabajo de campo. Pueblos tradicionales. Región fronteriza.

Data de recebimento: $23 / 11 / 2020$

Data de aprovação: 20/12/2020

\section{1 - INTRODUÇÃO}

A pesquisa foi realizada com a população indígena que se autodenomina Kaiowá no Brasil e Paĩ Tavyterã no Paraguai, por isso irei me referir ao grupo como Kaiowá - Paĩ Tavyterã residentes na região de fronteira situada nos territórios tradicionais Nande $\mathrm{Ru}$ Marangatu (Aldeia Campestre), no município de Antônio João, Estado de Mato Grosso do Sul/Brasil e, no Paraguai, na Colônia Pysyry, no Departamento de Amambay, Município de Pedro Juan Caballero. 
A população Guarani é uma das mais numerosas no Brasil, e o povo Kaiowá - Paĩ Tavyterã são representantes do subgrupo Kaiowá e pertencem ao tronco Tupi, da família linguística Tupi-guarani, que no Brasil engloba os Kaiowá, os Ñandeva e os Mby’a (PEREIRA, 1999, p. 14). São na maioria bilíngues, ou seja, além do Guarani, falam o português (Brasil) ou castellano/espanhol (Paraguai), todavia, os mais idosos falam somente a língua materna. A língua guarani é utilizada cotidianamente entre eles, em conversas, reuniões e ensinamentos dos "mais velhos" para as crianças e jovens. O povo Guarani tradicionalmente possui uma concepção de territorialidade ampla, englobando países como Paraguai, Brasil, Argentina e Bolívia. Esse território é denominado por esta população como Ñande Retã - "Nosso Território" - espaço no qual os Guarani vivem e estabelecem as suas comunidades.

Pensar a temática indígena atualmente implica em desfazer os equívocos gerados pela historiografia desse povo, sedimentada em preconceitos, o que também impulsionou essa pesquisa pela necessidade de desconstruir esses equívocos. Há cerca de seis anos, tive oportunidade de conviver com povos indígenas (Kamba, Guató, Kaiowá, Kadiwéu, Kinikinau e Terena) residentes no Estado de Mato Grosso do Sul, inicialmente através de pesquisa no período da graduação e depois por trabalhar voluntariamente na Ação Saberes Indígenas na Escola, sendo eternamente grata por tamanha oportunidade de aprendizagem e troca de conhecimentos. Lidar com os povos indígenas me fez compreender que apesar da história brasileira buscar manter esses povos no "passado", em realidade o que existe é uma população guerreira, que vivencia um período de transição marcado pelo conflito entre velhas e novas concepções que os levou a fazer adaptações em seu modus vivendi. Sendo assim, no trabalho de campo foi possível perceber que a Constituição Federal de 1988 fez com que os povos indígenas se fortalecessem e saíssem da invisibilidade no que se refere à luta por seus direitos territoriais (período em que se iniciou a retomada do TI Nande Ru Marangatu), valorização de suas línguas (conquistando espaços com Educação Indígena) e respeito às suas tradições.

O campo nos proporciona a prática do fazer antropológico, e pode-se dizer que esta ciência apresenta peculiaridades dentro das ciências humanas, trazendo a oportunidade de ampliar nossos conhecimentos através de fontes bibliográficas, mas, principalmente, através do trabalho de campo, que nos permite trazer aos leitores o que aprendemos sobre as diferenças culturais dos povos indígenas.

Cardoso de Oliveira (2006) retoma, e amplia, o tema da antropologia enquanto modalidade de conhecimento. O Trabalho do Antropólogo: olhar, ouvir, escrever de Roberto Cardoso de Oliveira constitui-se em uma reflexão sobre o trabalho do cientista social, mais especificamente do/a antropólogo/a. O autor enfatiza o caráter constitutivo do olhar, do ouvir e do escrever na elaboração do conhecimento próprio das disciplinas sociais. Destaco a visão desse autor, que afirma ser mais importante no início do trabalho antropológico a domesticação do "olhar", pois devemos ter em mente um olhar sobre a realidade humana. E com a escrita temos a possibilidade em transmitir conceitos que permeiam a noção de igualdade quanto a direitos e dignidade que estejam embasados na valorização da diversidade cultural, desconstruindo o etnocentrismo existente na sociedade. 
Cabe ressaltar que minha presença no trabalho de campo não foi de uma única estada prolongada junto ao grupo pesquisado, em comparação com os clássicos da Antropologia, como Boas (1883) e Malinowski (1922), que relatam ter convivido entre as populações estudadas por longos períodos. No entanto, minha convivência junto aos interlocutores foi suficiente para obtenção dos dados necessários para responder às indagações da pesquisa. Outro fator importante a destacar foi a resistência de alguns interlocutores durante a minha presença na comunidade, o que é perfeitamente compreensível, pois o estranhamento inicial entre as pessoas que não se conhecem é muito comum em qualquer ambiente. Apesar disso, obtive uma boa aceitação na comunidade principalmente após ir à campo, acompanhada pelo meu orientador, que outrora esteve presente na comunidade quando do confronto entre essa comunidade e a polícia em uma das retomadas do território tradicional, onde mais adiante explicarei melhor. Tal exemplo pode ser encontrado no episódio da Briga de Galos, descrita por Geertz (1989), em que vivenciou uma fuga impulsiva junto aos balineses diante da polícia javanesa em Bali/1958, e a partir daquele episódio, ganhou a confiança da comunidade.

Ao se abordar o estudo de grupos étnicos, a questão indígena se insere no pensar a identidade e, dentro de um panorama mais amplo, que seja capaz de abranger a construção da identidade de um povo como um processo dinâmico e segmentado, mas também ideológico e contraditório, justificando e legitimando as diferenças (DaMATTA, 1984). Nesse sentido, podemos dizer que os povos indígenas, em especial os fronteiriços, constantemente são questionados sobre sua verdadeira identidade étnica, entretanto o processo histórico-étnico de reconhecimento do povo Kaiowá não suscita quaisquer questionamentos sobre esse ponto, de tal modo que esta população não deveria passar por discriminação e muito menos qualquer dúvida quanto à sua identidade-étnica. "Guarani e Kaiowá: não se coloca em dúvida a sua identidade étnica indígena pois, apesar do longo período de contato com a sociedade nacional, eles mantêm sua língua e vários outros sinais diacríticos" (CAVALCANTE, 2014, p. 02).

Assim, podemos considerar que a prática da mobilidade dos Kaiowá - Paĩ Tavyterã, nas regiões de fronteira entre Brasil e Paraguai é mais um dos elementos que integram a dinâmica de sua constituição e permanência de sua identidade étnica, que os distingue dos grupos de matriz europeia e colonizadora, dos migrantes e dos nômades.

De acordo com Geertz, “[...] tornar-se humano é tornar-se individual, e nós nos tornarmos individuais sob a direção dos padrões culturais, sistemas de significados criados historicamente em termos dos quais damos forma, ordem, objetivo e direção às nossas vidas" (GEERTZ, 1989, p. 64). Dessa forma, compreendemos que a construção identitária faz parte da cultura de cada sociedade, e pode ser vista como um conjunto de mecanismos simbólicos erigidos para controlar e descrever o comportamento humano, mas na contrastividade cultural, onde a construção de uma identidade se dá ou afirma-se na negação de outra (BARTH, 2000), é que o grupo pesquisado se enquadra e enfrenta problemas por possuir na sua prática cultural e em sua identidade a mobilidade espacial, já que terminam por ser confundidos como simples migrantes ou até mesmo como povos nômades. 
Nesse trabalho busco apresentar brevemente a tradição do oguata ${ }^{3}$, atividade esta que faz parte da cultura tradicional do Kaiowá - Paĩ Taviterã, o conceito de territorialidade para o grupo pesquisado e, por último, minha experiência no campo.

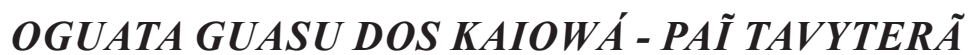

O fenômeno do oguata, ou seja, a mobilidade dos Guarani, costumam ocorrer dentro do mesmo território (tekoha guasu ${ }^{4}$ ), com intuito de buscar espaços que atendam às expressividades desta população, como regiões de mata, córrego e terras de agricultura (BRAND, 1997, p. 129).

Um outro fator para a mobilidade ocorrer é quando um grupo dissidente migra para outra terra, deixando que seus parentes permaneçam no lugar de origem podendo, assim, manter relações entre o novo e o antigo território (EMGC, 2016, p. 10).

A vida cotidiana dos Kaiowá - Paĩ Tavyterã, é caracterizada pela liberdade por ser uma população indígena sem fronteiras, ou melhor, sem as mesmas fronteiras impostas pelos Estados nacionais, que se resume à liberdade de ir e vir dentro do seu território, seja para visitar seus parentes, na busca de novos territórios, ou até mesmo poderem trabalhar e garantir o acesso à educação e saúde. Infelizmente, por residirem em região fronteiriça, os Kaiowá - Paĩ Tavyterã passam por obstáculos para se auto afirmar e autodeterminar, porque a sociedade não indígena frequentemente questiona a sua nacionalidade ocasionando grandes embaraços quanto ao acesso às políticas públicas em ambos os países estudados, em especial, pela falta de documentação.

Reiteramos que os povos indígenas fronteiriços por vezes sofrem dubiedade sobre sua identidade étnica, e os não indígenas os colocam em xeque quando se auto afirmam indígenas, dificultando a sua vida cotidiana no tocante ao acesso à educação, a programas de saúde e à previdência social.

Para a sociedade não indígena, é difícil compreender a prática cultural da mobilidade tradicional, visto que, inúmeras vezes, esse povo se depara com questionamentos sobre a motivação de seus deslocamentos, principalmente os residentes na fronteira, como é o caso do grupo pesquisado. Acrescenta-se a isso o fato de os Kaiowá - Paĩ Tavyterã falarem a língua Guarani, o que serve de justificativa para serem rotulados como "índios do Paraguai".

Importante destacar a dinâmica social dentro da comunidade, com a ocorrência de visitas entre os parentes e a participação das decisões envolventes nas famílias nucleares, inclusive entre a população transfronteiriça, como é o caso do território Nande Ru Marangatu,

3 Significa "caminhada ou bonita caminhada" também podendo encontrar na literatura como Ojeguata, que, segundo Colman (2015) quer dizer genericamente na língua Guarani "caminhar".

4 Em Guarani significa território grande. 
que foi divido ao meio quando da divisão dos Estados Nacionais (MELIÀ, 2016, p. 79).

O povo Kaiowá - Paĩ Tavyterã tem por tradição cultural a prática da mobilidade espacial. De acordo com Colman (2015, p. 20 apud VAINER E MELLO, 2012, p. 254), sua mobilidade espacial compreende os movimentos territoriais de uma população, englobando "a imigração e emigração de indivíduos, famílias ou grupos". O Oguata está vinculado ao direito consuetudinário ${ }^{5}$, que privilegia as práticas costumeiras e as tradições no seio de uma sociedade. A mobilidade espacial ao longo do território ancestral é uma prática milenar muito conhecida dentre os povos indígenas, associada à cosmologia, que é um dos elementos centrais da cultura desses povos, possibilitando o entendimento do seu modo de vida.

Nessa ótica, a mobilidade espacial praticada entre os Kaiowá - Paĩ Tavyterã está vinculada ao princípio da ancestralidade na relação com o território. Eles são povos agricultores que utilizam um sistema rotativo das terras, de forma a se evitar o desequilíbrio ecológico. Eles também praticam visitação a seus parentes, podendo ficar por meses e até mesmo anos, mantendo assim suas redes sociais e políticas. Outra causa não menos importante é o deslocamento para outros territórios abrangidos nos limites do tekoha guasu devido a conflitos internos, doenças, acidentes e imprevistos com parentes como, por exemplo, o falecimento de algum membro da família.

Para nossos interlocutores, o oguata faz parte da sua própria cultura, pois identifica-os como povo. Senhor Salvador por exemplo, relata-nos que na língua materna, fala-se que é Nande Reko, que significa "nosso modo de ser, nosso costume, nosso sistema e condição, nossa lei e hábito".

"Oguata para nós é caminhar, andar, passear e até mesmo ir encontrar trabalho". Essas narrativas descrevem que, com a caminhada, eles podem percorrer o tekoha guasu para caçar, pescar, trabalhar na roça, ajudar um parente na sua colheita, visitar um parente em outro tekoha, ou até mesmo ir até ao comércio na cidade de Antônio João, para comprar o que eles não conseguem plantar. Segundo narrativas, o hábito de caminhar se inicia ainda quando criança, pois elas costumam acompanhar os mais velhos, um dos momentos que é repassado as tradições culturais deste grupo.

\section{TERRITÓRIO - TEKOHA E TERRITORIALIDADE}

O território é um ambiente ocupado e utilizado de acordo com o sistema simbólico-cultural, ou seja, um espaço em que os Kaiowá - Paĩ Tavyterã vivem de acordo com sua organização social, identificado pelo grupo pesquisado como tekoha. Neste espaço territorial as representações simbólicas são valorizadas pelo grupo que ali vive em decorrência de um processo histórico de ocupação, onde vão sendo produzidas as manifestações e tradições culturais deste grupo.

5 Direito baseado nos costumes e nas práticas tradicionais e milenares, nem sempre reconhecidos pelo ordenamento jurídico ou pela lei vigente em um país. (Nota dos autores) 
Assim, "o território depende da ação social promovida por determinada sociedade que, por meio de sua prática, transforma o ambiente físico em ambiente social" (CRESPE, 2015, p. 171). Logo, podemos afirmar que para a comunidade Kaiowá - Paĩ Tavyterã, território é também o local de moradia, englobando uma área onde é possível lavrar suas plantações, caçar e pescar, cultivar plantas medicinais, praticar o Oguata (caminhada) entre as parentelas e suas alianças; enfim, viver de acordo com suas tradições culturais. Também podemos reafirmar que o fator histórico e a memória coletiva fazem com que o grupo mantenha uma relação com seu território tradicional, mantendo vínculos com o espaço onde seus antepassados viveram.

Segundo Cavalcante (2016, p. 33), os territórios não são construídos exclusivamente na relação de humanos com o ambiente, mas além destes há outros seres que habitam o território, podendo-se afirmar que os territórios tradicionais do Kaiowá - Paĩ Tavyterã são construídos em bases simbólicas, sociais e transcendentais.

Dentre as atividades do trabalho de campo, os momentos mais prazerosos eram aqueles em que estava sentada em frente à casa do Sr. Salvador, conversando com ele e rodeada por pessoas de sua família, sempre tomando um tereré que circulava pela roda. Durante uma dessas conversas, meu interlocutor falou sobre o significado deste importante conceito: de acordo com o Sr. Salvador "tekoha é o modo de ser, onde tem animais, plantio, remédio para qualquer doença que se tenha [...]". Ao ouvir tais palavras, e como descreveu seu território antes de seus parentes praticarem a mobilidade forçada para o Paraguai, foi possível compreender que tekoha para os Kaiowá - Paĩ Tavyterã é o lugar físico que contém matas (ka'aguy) e todo o ecossistema, como animais para caça, água fresca, matéria prima para casas e artefatos, frutos para coleta, plantas medicinais etc. Lugar este que sempre era lembrado por ele e por seus familiares no período em que viveram do outro lado da fronteira, na Colônia Pysyry, no Paraguai, próximo ao córrego Takuara e ao cerro Avaká.

Os estudos demonstram que tekoha é o lugar em que a comunidade Kaiowá - Paĩ Tavyterã vive de acordo com sua tradição cultural. Habitualmente este espaço não é muito populoso, podendo ser encontrado nele de duas a cinco famílias extensas. Em sua pesquisa, Lucas relata que "esse número de pessoas varia quanto ao número de parentelas e a quantidade de indivíduos que um chefe de prestígio consegue agregar em torno de si, seja os familiares ou os aliados" (LUCAS, 2017, p. 74).

Para este povo, tekoha pode ser representado por terra ou território. Terra no sentido de reprodução de seus valores culturais, de importância para produção e manutenção do seu grupo, assegurando a existência material de seus familiares, mas não para acumular riqueza (EMGC, 2016).

Entende-se que, para os Kaiowá - Paĩ Tavyterã, a forma que um grupo social assume fisicamente no espaço não é algo definitivamente dado e imutável. Sua formação é um fato histórico, em contínua transformação e adaptação às condições do contexto territorial onde 
tal grupo desenvolve suas atividades.

O surgimento de um território se dá através das condutas de territorialidade de um grupo social, partindo de um processo histórico, social e político (LITTLE, 2002). O autor nos afirma que, para uma análise antropológica da territorialidade, faz-se necessária uma abordagem etnográfica para que se possa compreender a diversidade de territórios, para tanto nos traz o conceito de cosmografia.

Lembrando Little (2002, p. 255), a "conduta territorial entra em choque" com a territorialidade de outros grupos, no momento que ocorre uma expansão de territórios, nesse sentido compreendemos os conflitos ocorridos ao longo dos últimos anos entre terceiros (colonização e agronegócio) e os povos tradicionais.

O povo Kaiowá - Paĩ Tavyterã se insere na abordagem de questões sobre a imposição de novas configurações territoriais a que esse povo foi submetido devido à colonização da área de fronteira, que impactou a forma organizacional dessa população e, mesmo assim, com base na sua territorialidade, continuam se organizando para manter a cultura tradicional.

\section{2 - VIVÊNCIAS E EXPERIÊNCIA NO CAMPO'}

As dificuldades no trabalho de campo junto aos povos tradicionais Kaiowá - Paĩ Tavyterã, foram inúmeras. A primeira delas foi a barreira linguística, afinal por mais que a maioria dos interlocutores seja bilíngue, ainda assim existe dificuldade na interpretação da língua portuguesa, pois há conceitos na língua guarani sem interpretação, ocorrendo o mesmo no lado paraguaio, em que a comunidade é trilíngue. Mesmo assim, ainda conseguiam compreender boa parte do que eu falava, entretanto, eu não compreendia quase nada do que eles falavam. A primeira ida a campo, também foi o primeiro contato com falantes da língua guarani, momento em que constatei que não conseguiria continuar a pesquisa sozinha, necessitando ajuda de alguém para me acompanhar no campo. Felizmente, consegui a companhia da pesquisadora Rosa Colman, a quem sou eternamente grata, a qual, além de pesquisar na mesma região, domina perfeitamente a língua guarani. Um outro fator de dificuldade foi o clima, pois tanto no início do trabalho de campo, como no final, ocorreram fortes chuvas na região, inviabilizando o acesso às comunidades, principalmente à Colônia Pysyry, cujo acesso se dá pela travessia do Córrego Takuara, impossibilitando atravessar com veículo devido a cheia, pois não há ponte no local.

Inúmeras vezes fui até a TI Ñande Ru Marangatu para buscar o senhor Salvador, interlocutor que me acompanhou em todas as vezes que fui até a Colônia Pysyry, do lado paraguaio. Ele viveu por mais de dez anos nesta região com sua família, após ser expulso do seu tekoha apenas com a roupa do corpo. Saiu de Ñande Ru Marangatu temendo a violência física e psicológica praticada pelas frentes agropastoris na região pesquisada no final da década de

6 Este relato é parte da dissertação de mestrado: KAIOWÁ-PAĨ TAVYTERÃ: ONDE ESTAMOS E AONDE VAMOS? Um estudo antropológico do Oguata na fronteira Brasil/Paraguai, defendida em fevereiro de 2019, junto ao Programa de Pós-Graduação em Antropologia Social da Universidade Federal de Mato Grosso do Sul, sob orientação do Prof. Dr. Antonio Hilario Aguilera Urquiza. 
1940 e início da década de 1950, e essa situação se estendeu até a década de 1970, forçando a mobilidade desta população, principalmente para o outro lado do rio Estrela, no Paraguai, onde está a Colônia Pysyry.

Nas inúmeras tentativas em ir para o campo no lado paraguaio, sempre ocorria algum impedimento ou problema: ora eram as questões climáticas, ora ocorriam outros infortúnios, como indisposição do senhor Salvador ou de algum parente, ou a perda de algum parente no território. Destaco que busquei sempre respeitar as tradições culturais, o tempo deles, aguardando a disponibilidade para contribuir com a minha pesquisa.

Com o passar dos meses e tantas idas e vindas, sem avançar com dados novos para a pesquisa, as aflições se afloravam, o desespero tentava me dominar, mas as contribuições dos clássicos da antropologia não me deixavam abater perante as dificuldades. Acredito que o grupo estava me testando para verificar se eu realmente tinha disposição para pesquisar no território, e poder me conhecer um pouco mais; não tiro a razão, pois também não abrimos as portas de nossa casa para qualquer pessoa.

Um outro fator foi que eu queria fazer o trajeto do oguata até as margens do rio Estrela que faz divisa entre os dois países. O trajeto seria para marcar a distância percorrida pelo povo local nas visitações ou até mesmo para a prática da pesca. Eles apontavam, é logo ali, próximo àquela morraria, mas em cada visita a alguma parentela dentro do território, percorríamos vários quilômetros de carro e, chegando ao local, a mesma situação se repetia "Está vendo a morraria? É logo ali o rio Estrela". Mesmo percebendo que era uma longa distância, ficava animada e me preparava, organizava a viagem de campo e chegando no local, ouvia, uma desculpa, "o dia está muito quente, a senhora não vai aguentar andar tanto, o sol vai queimar sua pele, vocês não estão acostumados a caminhar, o vento diz que vai chover, etc." No fundo não queriam me dizer que no meio da trilha que os levava ao rio através da prática do oguata, encontra-se fazendas e propriedades de particulares que os impedem de manter a prática milenar. Como já vimos anteriormente, o povo Kaiowá - Paĩ Tavyterã praticam o oguata para caça, pesca, visita a seus parentes consanguíneos e até para participação em reuniões políticas (Aty guassu) e festividades religiosas. Entretanto isso não é possível atualmente, pois eles têm receio e sofrem ameaças de invasão por parte dos fazendeiros que os expulsaram de seu território tradicional anos atrás como descrito anteriormente, fato este usado como desculpa para não me levarem até o rio, como forma de preservar minha integridade física.

Percebi que as dificuldades que eu enfrentava não eram por questões de gênero, mas simplesmente por eles ainda não confiarem na minha presença no território, o que é compreensível, até porque, às vezes deixavam escapar que alguns pesquisadores passaram pelo território e nunca mais voltaram. Por isso, é importante nós pesquisadores termos a ética de darmos o retorno dos resultados da pesquisa à comunidade após a conclusão, em significado de respeito ao grupo pesquisado e à comunidade acadêmica, pois uma má conduta do pesquisador pode fechar portas para futuros cientistas. Além disso, importante também, o comprometimento com a causa indígena e a defesa de seus direitos.

Mesmo percebendo que após inúmeras idas ao território tradicional e que ainda não havia conquistado plenamente a confiança da população local, persisti e continuei indo, e viajava 
aproximadamente $410 \mathrm{~km}$ da capital até o TI Ñande Ru Marangatu. Em um dia agendado para ir ao TI o meu companheiro de viagem não poderia ir devido a outro compromisso e, sendo assim, convidei o meu orientador para me acompanhar no campo. Chegando na área, ele comentou que esteve no local em 2005, no dia em que o território recebeu um mandado judicial para desocupação da terra, local este que foi homologado como terra indígena Nhanderu Marangatu pelo presidente Luiz Inácio Lula da Silva, em março de 2005. Porém o TRF (Tribunal Regional Federal) da $3^{\text {a }}$ Região, em São Paulo, suspendeu a demarcação da área de 9.000 hectares e em setembro deste mesmo ano determinou a desocupação.

A reação dos indígenas foi imediata. Ao descrever que esteve junto deles naquele momento de grande violência (eram dezenas de militares da força anti distúrbios, soldados a cavalo, Polícia Federal, helicóptero, etc.), os mais velhos recordaram os fatos e sentiram confiança na "pesquisadora". A partir daí, passaram a nos levar em locais que antes eu nunca havia estado nos campos anteriores, e olha que não foram poucas, inclusive a margem do córrego estrelinha, um outro local que também não consegui chegar anteriormente. A partir deste dia, mesmo não estando em companhia do meu professor os moradores já não se sentiam tão intimidados com minha presença, sendo assim, eu deixava de ser o objeto de análise do grupo pesquisado, tornando-me ainda mais conhecida no território surgindo, assim, momento muito significativo no trabalho de campo, em que ocorria as rodas de conversa em cada tekoha que chegávamos.

Cada vez mais, nossos interlocutores me levavam para conhecer seus parentes, colaboravam com pequenas atividades familiares, inclusive em algumas visitas já podia participar das refeições junto com a parentela. Eu e meu esposo, companheiro de viagem, ganhamos apelidos na língua: eu Puku (ser alta), provavelmente por ter estatura bem acima das mulheres Kaiowá e, meu esposo Karape (baixo), apesar de não ser, e com sorrisos constantes eles tentavam nos ensinar algumas palavras em guarani, confesso que aprendi pouquíssimas.

Após essas experiências, sentindo-me mais integrada ao grupo, consegui dados para compor a pesquisa e sanar minhas dúvidas sobre o território. As inquietações eu não digo que sanei todas, pois ao longo da pesquisa sempre vão surgindo novos questionamentos que o período vigente do mestrado não dá conta por ser curto demais. Destaco que a vivência e experiência de campo foi, e sempre será, muito prazerosa, além de enriquecer nossos conhecimentos, eu aprendi com esse povo guerreiro o valorizar ainda mais a natureza, a família e amigos. De forma simples foi possível através de sua sabedoria proporcionar grande aprendizagem sobre suas tradições culturais. Foram responsáveis pela inspiração na produção do trabalho, cada sorriso, emoção, ensinamento, a força no olhar com quem tive oportunidade de conviver ficará eternizado em minha memória. Não tenho palavras para descrever tamanha admiração e gratidão, Aguyjé! 


\section{3- APONTAMENTOS FINAIS}

Ao descrever alguns fatos cotidianos da experiência do campo e seus impasses, espero ter contribuído para as questões da metodologia aplicada ao trabalho de campo. Cabe ressaltar que, no trabalho de campo, os caminhos a serem seguidos devem ser bem delineados, respeitando o grupo pesquisado e suas tradições culturais, além de respeitar o tempo que a comunidade tem para nos conhecer. $\mathrm{O}$ território indígena oferece um amplo campo de investigações, seja quanto aos aspectos econômicos, sociais, políticos e culturais. Assim, entendemos que com respeito e diálogo a etnografia nos proporciona contribuições relevantes que, em parte, buscamos apresentar e esperamos ter alcançado esse objetivo. 


\section{4 - REFERÊNCIAS}

BARTH, Fredrik. O guru, o iniciador e outras variações antropológicas. Tradução de John Cunha Comerford. Rio de Janeiro: Contra Capa Livraria, 2000.

BRAND, Antonio Jacó. O impacto da perda da terra sobre a tradição Kaiowa/Guarani: os difíceis caminhos da Palavra. Tese (Doutorado em História) - Pontifícia Universidade Católica do Rio Grande do Sul, Porto Alegre. 1997.

BOAS, Franz. Antropologia cultural. Trad. Celso Castro - 4. Ed. - Rio de Janeiro: Zahar Ed. 2004. CAVALCANTE, Thiago Leandro Vieira. Os Guarani Transfronteiriços: A Realidade de quem existesem existir, 2014. Disponível em: <http:/historiaehistoria.com.br/materia.cfm?$\mathrm{tb}=$ artigos\&id=264> Acesso em 15/10/2016.

CARDOSO DE OLIVEIRA, Roberto. O trabalho do antropólogo. $2^{\circ}$ edição. Editora UNESP: SP, 2006.

COLMAN, Rosa Sebastiana. Guarani Retã e Mobilidade Espacial Guarani: belas caminhadas e processos de expulsão no território Guarani. Tese (Doutorado em Demografia) - Universidade Estadual de Campinas, Campinas/SP. 2015.

CRESPE, Aline Castilho Lutti. Mobilidade e temporalidade Kaiowá: do tekoha à reserva, do tekoharã ao tekoha. Tese (Doutorado em História) Universidade Federal da Grande Dourados, Dourados/MS. 2015.

DaMATTA, R. Relativizando: uma introdução à antropologia social. Petrópolis: Vozes, 1984.

EMGC, Equipe Mapa Guarani Continental. Caderno Mapa Guarani Continental: povos Guarani na Argentina, Bolívia, Brasil e Paraguai. Campo Grande, MS. CIMI, 2016.

GEERTZ, Clifford. A interpretação das culturas. Rio de Janeiro: LTC, 1989.

LITTLE, Paul E. Territórios sociais e povos tradicionais no Brasil: por uma antropologia da territorialidade. Brasília: UnB, 2002. Série Antropologia $n^{\circ} 322$. 32p. Disponível:http:// periodicos.unb.br/ojs311/index.php/anuarioantropologico/article/view/6871. Acesso em: 05/10/2018.

LUCAS, Sônia Rocha. Crianças indígenas no acampamento Pakurity-MS: quem são, como vivem e como percebem a situação de moradias móveis. Dissertação (Mestrado em Antropologia) - Universidade Federal da Grande Dourados. Dourados, MS, 2017.

MALINOWSKI, Bronislaw. Argonautas do Pacífico Ocidental: um relato do empreendimento e da aventura dos nativos nos arquipélagos da Nova Guiné Melanésia. 3. ed. São Paulo: Abril Cultural, 1984.

PEREIRA, Levi Marques. Parentesco e organização social Kaiowá. Dissertação (Mestrado em antropologia) - Universidade Estadual de Campinas. Campinas, SP. 1999. 